\title{
Michel Simonin, L'Encre Et La Lumière
}

\section{Michele Mastroianni}

\section{(2) OpenEdition}

\section{Journals}

\section{Edizione digitale}

URL: http://journals.openedition.org/studifrancesi/34453

DOI: 10.4000/studifrancesi.34453

ISSN: 2421-5856

\section{Editore}

Rosenberg \& Sellier

\section{Edizione cartacea}

Data di pubblicazione: 1 novembre 2005

Paginazione: 396-397

ISSN: 0039-2944

\section{Notizia bibliografica digitale}

Michele Mastroianni, «Michel Simonin, L'Encre Et La Lumière», Studi Francesi [Online], 146 (XLIX | II) |

2005, online dal 30 novembre 2015, consultato il 20 avril 2021. URL: http://journals.openedition.org/ studifrancesi/34453; DOI: https://doi.org/10.4000/studifrancesi.34453

\section{Questo documento è stato generato automaticamente il 20 avril 2021.}

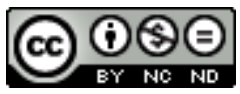

Studi Francesi è distribuita con Licenza Creative Commons Attribuzione - Non commerciale - Non opere derivate 4.0 Internazionale. 


\title{
Michel Simonin, L'Encre Et La Lumière
}

\author{
Michele Mastroianni
}

\section{NOTIZIA}

MICHEL SIMONIN, L'Encre Et La Lumière, Genève, Droz («Travaux d'Humanisme Et

Renaissance», CCCXCI), 2004, Pp. XX+871.

Come omaggio alla memoria di Michel Simonin, prematuramente scomparso nel novembre del 2000, un gruppo di amici e colleghi ha raccolto quarantasette articoli, editi e inediti, che testimoniano dell'attività di maestro della cinquecentistica del grande studioso e offrono validi strumenti di lavoro e di ricerca agli specialisti del XVI secolo. Viene in qualche modo ritracciato l'itinerario intellettuale del biografo ed editore di Ronsard e dello specialista di Montaigne, secondo le quattro grandi direttive della sua attività. Anzitutto, in ordine di tempo, sono ampiamente attestati gli interessi di Simonin per la novellistica, con una speciale attenzione a problemi di ricezione, di diffusione libraria e di statuti narrativi; in particolare, mostrando interesse per la fortuna francese di Bandello: Notes sur Pierre Boaistuau (pp. 3-14); Traduction et pédagogie des langues au XVI ${ }^{e}$ siècle: sur un ouvrage de Pierre Boaistuau mis en latin par Bénigne Poissenot (pp. 15-18); Boaistuau et Bruscambille: note sur le texte des 'Imaginations' (pp. 19-24); Michel de Nostredame, Pierre de Boaistuau, Chavigny et la peste aixoise de 1546 (pp. 25-28); François de Belleforest traducteur de Bandel dans le premier volume des 'Histoires tragiques' (pp. 29-45); Le retour de Martin Ponthus: trajets d'une rumeur, des 'Comptes du monde adventureux' aux 'Novelle' de Bandello (pp. 47-67); La publication et la traduction de 'La quarta parte de le Novelle' de Bandello (pp. 69-83); Un conteur tenté par le savoir: Guillaume Bouchet correcteur de sa III 'Serée' (pp. 85-106); Autour du 'Traicté paradoxique en dialogue' de Bénigne de Poissenot (pp. 107-120); Bebel en France au XVI' (pp. 121-141); Enquête sur les 'Escraignes' (pp. 143-153); L'héritage de la Renaissance dans le 'Chasse-ennuy' de Louis Garon (pp. 155-162); Le statut de la description à la fin de la Renaissance (pp. 163-177); La réputation des 
romans de chevalerie selon quelques listes de livres (pp. 179-187); La disgrâce d' 'Amadis' (pp. 189-234).

In una seconda sezione sono ordinati saggi e interventi intorno al polo di ricerca che da solo basterebbe a rendere Simonin cinquecentista insigne. Si tratta di articoli su Ronsard che concernono la poetica di questo autore, ma che sono soprattutto mirati a precisare dati storici e filologici e ad apportare materiale erudito nuovo: Ronsard et la poétique des 'CEuvres' (pp. 237-251); 'Poësie est un pré', 'Poëme est une fleur': métaphore horticole et imaginaire du texte à la Renaissance (pp. 253-263); Ronsard et la tradition de l' 'épitaphios' (pp. 265-278); Hélène avant Surgères: pour une lecture humaniste des 'Sonnets pour Hélène' (pp. 279-296); Ronsard et l'exil de l'âme (pp. 297-310); Sur le personnel du premier livre des 'Hymnes' (pp. 311-319); Ronsard, Claude Haton et Catherine de Médicis: un document inédit sur le 'Discours des misères de ce temps' (pp. 321-333); Ronsard encomiaste (pp. 335-350); Ronsard et l'anagramme (pp. 351-371); Les relations de Des Masures avec Dorat et Ronsard (pp. 373-394); L'apothéose de Ronsard dans l' 'Oraison funèbre' de Du Perron (pp. 395-404).

3 L'altro grande polo di ricerca, quello su Montaigne, è rappresentato, in una terza sezione, da articoli che affrontano il grande moralista da due punti di vista, quello dei problemi posti dall'edizione degli Essais e quello della ricostruzione di rapporti con esponenti della vita culturale dell'epoca attraverso lo studio di documenti inediti o rari: Poétique(s) du politique: Montaigne et Ronsard prosopographes de Fançois de Guise (pp. 407-426); CEuvres complètes ou plus que complètes? Montaigne éditeur de La Boétie (pp. 427-456); Les papiers de La Boétie, Thomas de Montaigne et l'édition de la chorographie du Médoc (pp. 457-488); Montaigne et ses frères: un poème inédit de Georges Buchanan (pp. 489-508); Le Périgourdin au Palais: sur le voyage des 'Essais', de Bordeaux à Paris (pp. 509-522); Aux origines de l'édition de 1595 (pp. 523-549); Montaigne, son éditeur et le correcteur devant l'exemplaire de Bordeaux (pp. 551-569); Montaigne et les Feuillants (pp. 571-596); Eléonore de Montaigne (pp. 597-645); Notes sur les voyages et la reliure de l'exemplaire de Bordeaux des 'Essais' de Montaigne (pp. 647-661).

Una quarte sezione, infine, raccoglie saggi consacrati a problemi di politica editoriale da parte dei libraires cinquecenteschi e di diffusione del libro: Eros aux $\mathrm{XVI}^{e}$ et XVII ${ }^{e}$ siècles: les limites du savoir (pp. 665-680); De Marot à Ronsard: les 'Traductions de Latin en François' (1550 et 1554) (pp. 681-703); De la prime fortune éditoriale des nouvelles de Marguerite de Navarre (pp. 705-718); La version primitive inédite de l' 'Histoire des délivrances de la ville de Sancerre' de Jean de Léry (pp. 719-726); Poétiques des éditions 'à l'essai' au XVI siècle (pp. 727-745); Des projets littéraire et de leurs réalisations éditoriales à la Renaissance (pp. 747-760); Peut-on parler de politique éditoriale au XVI siècle? Le cas de Vincent Sertenas, libraire du Palais (pp. 761-782); Les contrefaçons lyonnaises de Montaigne et Ronsard au temps de la Ligue (pp. 783-802); Des livres pour l'Europe? Réflexions sur quelques ouvrages polyglottes (pp. 803-814); La méditérranée à l'assaut de Paris: Pierre du Buisson, ses catalogues et ses livres (pp. 815-830); Réflexions sur un catalogue d'amateur (pp. 831-838). 